\title{
Study on the Molecular Immunology Control between Type I and II Schizophrenics
}

\author{
Wan Feng Li $\mathbf{i}^{1, a}$ \\ ${ }^{1}$ Changsha Medical University, Changsha, China, 410219 \\ a425680231@qq.com
}

Keywords: Type I; Type II; Schizophrenia

\begin{abstract}
Objective To explore the reference value of molecular immunological detection in the clinical diagnosis and treatment of type I and II schizophrenics. Methods 86 type I and II schizophrenics admitted and treated in our hospital from February 2015 to January 2017, together with 45 healthy subjects receiving molecular immunological detection at the same period were treated as the objects of study. They were divided into group I $(n=41)$, group II $(n=45)$ and control group ( $n=45)$. The molecular immunological detection results in each group of subjects were compared. Results Compared with control group, IgG and C4 levels in group I were remarkably higher, while IgM level was notably lower; meanwhile, IgA, IgM, IgG and C4 levels in group II were evidently higher. Compared with group I, IgM level in group II was distinctly higher, with the difference being statistically significant $(\mathrm{P}<0.05)$. The prognostic recovery effect in group I was superior to that in group II after treatment $(\mathrm{P}<0.05)$. Conclusion Molecular immunological detection results have certain reference value to the clinical diagnosis and treatment for type I and II schizophrenics.
\end{abstract}

\section{Introduction}

Schizophrenia is a severe mental disease, which has serious damage to both the physical and mental health of patients. The etiology of schizophrenia remains unclear, which has added to the difficulty in clinical diagnosis and treatment. Schizophrenia has different classifications, with type I and II schizophrenia being the most common. The different etiology has led to difference in treatment. The clinical treatment of schizophrenia can hardly be determined completely based on the clinical symptoms and signs of patients. In contrast, the differences between type I and II schizophrenics should also be compared in combination with molecular immunological analysis [1]. 86 type I and II schizophrenics admitted and treated in our hospital were treated as the objects of study in this research. The details were reported as follows.

\section{Materials and methods}

\section{General information}

86 type I and II schizophrenics admitted and treated from February 2015 to January 2017 in our hospital were treated as the objects of study. Of them, 41 were type I schizophrenics and 45 were type II schizophrenics, and they were divided into group I and group II. Additionally, 45 healthy subjects receiving molecular immunological detection at the same period were served as the control group. 22 cases in group I were male, while 19 were female, with the age ranging from 29 to 75 (mean: $44.5 \pm$ 8.2) years. 24 cases in group II were male, while 21 were female, with the age ranging from 32 to 76 (mean: $43.9 \pm 7.1$ ) years. 26 cases in the control group were male, while 19 were female, with the age ranging from 30 to 72 (mean: $42.8 \pm 7.5$ ) years. The baseline data of three groups were comparable ( $\mathrm{P}>0.05$ ), thus this research was feasible. 


\section{Methods}

Patients in group I and II received venous blood sampling in the morning. The blood samples were centrifuged and the serum was separated. Serum IgG, IgA, IgM, C3 and C4 index levels were determined by means of immunological transmission turbidimetry using TBA-2000FR automatic biochemical analyzer (Toshiba Medical System Corporation) and immunoglobulin detection kit (Shanghai Beijia Biochemical Reagent Co., Ltd).

\section{Statistical processing}

Data were processed and analyzed using the SPSS19.0 statistical software.

Measurement and enumeration data were expressed as $\left({ }^{X} \pm \mathrm{s}\right)$ and $(\%)$, respectively, which were tested using t-test and chi-square test. Difference of $\mathrm{P}<0.05$ suggested statistically significant difference.

\section{Results}

\section{Immunoglobulin index levels in each group}

Table 1. Immunoglobulin index levels in each group $\left({ }^{X} \pm \mathrm{s}\right)$

\begin{tabular}{clcc}
\hline Group & IgG $(\mathrm{g} / \mathrm{L})$ & $\operatorname{IgA}(\mathrm{g} / \mathrm{L})$ & $\operatorname{IgM}(\mathrm{g} / \mathrm{L})$ \\
\hline Group I $(\mathrm{n}=41)$ & $13.05 \pm 1.02^{*}$ & $2.05 \pm 1.01$ & $1.11 \pm 0.32^{*}$ \\
Group II $(\mathrm{n}=45)$ & $14.52 \pm 2.81^{*}$ & $2.55 \pm 0.98^{*}$ & $1.75 \pm 0.38^{*} \#$ \\
$\begin{array}{c}\text { Control group } \\
(\mathrm{n}=45)\end{array}$ & $10.42 \pm 1.64$ & $1.79 \pm 0.82$ & $1.39 \pm 0.48$ \\
\hline
\end{tabular}

Note: compared with control group. ${ }^{*} \mathrm{P}<0.05$; compared with group I, \# $\mathrm{P}<0.05$.

\section{Complement contents in each group}

Table 2. Complement contents in each group $\left(X_{ \pm s}\right)$

\begin{tabular}{ccc}
\hline Group & C3 $(\mathrm{g} / \mathrm{L})$ & C4 $(\mathrm{g} / \mathrm{L})$ \\
\hline Group I $(\mathrm{n}=41)$ & $1.31 \pm 0.48$ & $0.38 \pm 0.09^{*}$ \\
Group II $(\mathrm{n}=45)$ & $1.39 \pm 0.52$ & $0.36 \pm 0.10^{*}$ \\
Control group $(\mathrm{n}=45)$ & $1.19 \pm 0.22$ & $0.22 \pm 0.06$ \\
\hline
\end{tabular}

\section{Mental symptoms in type I and II schizophrenics}

Table 3. Mental symptoms in type I and II schizophrenics $\left({ }^{X} \pm \mathrm{s}\right)$

\begin{tabular}{ccc}
\hline Group & SAPS score & SANS score \\
\hline Group I $(\mathrm{n}=41)$ & $32.14 \pm 5.13$ & $24.71 \pm 4.96$ \\
Group II $(\mathrm{n}=45)$ & $23.54 \pm 5.73$ & $36.25 \pm 5.23$ \\
P-value & & $<0.05$ \\
\hline
\end{tabular}




\section{Social function of type I and II schizophrenics after treatment}

\begin{tabular}{cccc}
\multicolumn{4}{c}{ Table 4. Social function evaluation in type I and II schizophrenics after treatment $\left(X_{ \pm \mathrm{s}}\right)$} \\
\hline Group & $\begin{array}{c}\text { Activity of } \\
\text { daily living }\end{array}$ & $\begin{array}{c}\text { Initiative and } \\
\text { intercourse }\end{array}$ & Social skill \\
\hline Group I $(\mathrm{n}=41)$ & $11.25 \pm 1.42$ & $11.75 \pm 2.46$ & $10.12 \pm 2.75$ \\
Group II $(\mathrm{n}=45)$ & $9.12 \pm 1.19$ & $9.28 \pm 1.95$ & $8.56 \pm 1.44$ \\
P-value & & $<0.05$ & \\
\hline
\end{tabular}

\section{Discussion}

The incidence of schizophrenia is mainly affected by endogenous factors (organic disease and mental factors) and exogenous factor (external environment). However, the precise cause remains unclear. It can damage the physical and mental health of patients in the meantime of affecting the normal family and social life of patients. Schizophrenia can be classified into type I and II schizophrenia based on the differences in clinical symptoms, cognitive function and biological foundation of schizophrenics. Type I schizophrenia shows the positive symptoms like delusion and hallucination, along with no remarkably changed cognitive function and dopamine hyperfunction. Type II schizophrenia presents as negative symptoms like indifference and poverty of speech. Their cognitive function has changed, together with loss and degeneration of brain cell, as well as no distinctly changed dopamine function. Type I schizophrenics have good response when treating with neuroleptics, while type II schizophrenics have poor response. The pathogenic factors should be further understood in the clinical treatment of type I and II schizophrenia. Importantly, molecular immunological analysis allows for detection based on the differences in immunoglobulin index levels and complement contents. Research indicates that schizophrenia is an immune pathological damage occurring in the central nervous system. It is related to immune pathological changes induced by circulating immune complexes and antibodies produced by humoral immunity [2].

Results in this research suggest that IgG and C4 levels in type I schizophrenics are markedly higher than those in normal subjects, while IgM level is lower than that in control group. Moreover, IgA, IgM, IgG and C4 levels in type II schizophrenics are distinctly higher than those in normal subjects, and IgM level is evidently higher than that in type I schizophrenics. The differences in the above comparisons are statistically significant $(\mathrm{P}<0.05)$. Social function scores of type II schizophrenics in activity of daily living, initiative and intercourse, as well as social skills are all lower than those of type I schizophrenics. This has suggested that type I schizophrenics have superior prognostic effect than type II schizophrenics.

\section{Conclusion}

To sum up, abnormal body immunological response can provide certain reference for the clinical treatment of type I and II schizophrenics. However, it can hardly guarantee its accuracy, which requires further intensive studies.

\section{References}

[1] Dencker S J, Frankenberg K, Hansen V, et al. Clopenthixol and flupenthixol depot preparations in outpatient schizophrenics. II. Factor analysis of the, CPRS sub-scale for schizophrenia.[J]. Acta Psychiatrica Scandinavica, 2010, 61(S279):29-40.

[2] Reutfors J, Bahmanyar S, Jönsson E G, et al. Medication and suicide risk in schizophrenia: a nested case-control study[J]. Schizophrenia Research, 2013, 150(2-3):416-420. 